\title{
RESISTÊNCIA E CRIAÇÃO: MICROPOLÍTICA DAS VIOLÊNCIAS E SUBJETIVAÇÃO DO MEDO NO CONTEXTO DA CIÊNCIA E DA DEMOCRACIA
}

RESISTANCE AND CREATION: MICROPOLITICS OF VIOLENCE AND SUBJECTIFICATION OF FEAR IN THE CONTEXT OF SCIENCE AND DEMOCRACY

RESISTENCIA Y CREACIÓN: MICROPOLÍTICA DE LAS VIOLENCIAS Y SUBJETIVACIÓN DEL MIEDO EN EL CONTEXTO DE LA CIENCIA Y DE LA DEMOCRACIA

Maria Elizabeth Barros de Barros*

\begin{abstract}
RESUMO
$\mathrm{O}$ artigo apresenta algumas formulações sobre o contemporâneo, marcado por uma espécie de epidemia de violência e uma pandemia do medo. Destaca que a produção desse medo se torna um instrumento de dominação, o que faz prevalecer interesses individualistas que minam o espaço público. Tal direção de análise baseia-se nas formulações de Hannah Arendt e Agamben. Apresenta, ao final, uma experiência em universidade pública na Região Sudeste do Brasil, que se constituiu como estratégia de enfrentamento a esse estado de coisas, vislumbrando políticas efetivamente públicas no campo da educação.
\end{abstract}

Palavras-chave: Resistência. Criação. Educação. Contemporâneo.

\begin{abstract}
This article brings some issues about the contemporaneity, marked by a kind of epidemic of violence and a pandemic of fear. It also highlights that the production of this kind of fear becomes a device of domination, that makes individualistic interests prevail, which undermine public space. This direction of analysis is based on Hannah Arendt's and Agamben's statements. At the end, it shows an experiment in a Public University in the Southeastern Region of Brazil that turned into a strategy to face this state of affairs, envisioning effectively public policies in the education field.
\end{abstract}

Keywords: Resistance. Creation. Education. Contemporary.

"Doutora em Educação e Sociedade pela Universidade Federal do Rio de Janeiro (UFRJ), professora titular do Departamento de Psicologia da Universidade Federal do Espírito Santo (UFES), psicóloga. Endereço: Avenida Saturnino de Brito, $915 / 302$ Praia do Canto, Vitória-ES, Brasil. CEP: 29055-180. Telefones: (27) 3227-0853 e (27) 99923-2411. E-mail: betebarros@uol. com.br. 


\section{RESUMEN}

El artículo presenta algunas formulaciones sobre el contemporáneo marcado por una especie de epidemia de violencia y una pandemia del miedo. Además, pone de relieve que la producción de ese miedo se convierte en un instrumento de dominación, lo que hace prevalecer intereses individualistas, que socavan el espacio público. Tal dirección de análisis se basa en las formulaciones de Hannah Arendt y Agamben. Al final, presenta una experiencia en una Universidad Pública en la Región Sureste de Brasil, que se constituyó como estrategia de afrontamiento a ese estado de cosas, vislumbrando políticas efectivamente públicas en el campo de la educación.

Palabras-clave: Resistencia. Creación. Educación. Contemporáneo.

\section{INTRODUÇÃO}

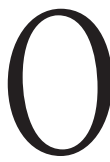
título deste artigo é provocador. Tema que nos convoca a uma postura atencional ao presente. Como nos diz Agamben (2009), é verdadeiramente contemporâneo aquele que não coincide perfeitamente com o seu tempo, nem está adequado às suas pretensões, é, portanto, inatual e, exatamente por isso, por meio desse deslocamento e desse anacronismo, é capaz de perceber e apreender seu tempo. "Aqueles que coincidem muito plenamente com a época, que em todos os aspectos a esta aderem perfeitamente, não são contemporâneos porque, exatamente por isso, não conseguem vê-la, não podem manter fixo o olhar sobre ela" (Agamben, 2009, p. 59).

Assim, é buscando ser inatual e não coincidir com nossa época que este texto se estrutura. Partimos de algumas formulaçôes de Teixeira (2004), em seu artigo intitulado Redes de trabalho afetivo e a contribuição da saúde para a emergência de uma outra concepção de público, no qual afirma que vivemos momentos de uma desigualdade que se expressa pela proliferação de todas as formas de desqualificação e pela produção de indivíduos desnecessários. Uma espécie de epidemia de violência, diz ele, ou como formulado por Breilh (2004), uma pandemia $^{1}$ do medo, que tem pautado nossos modos de viver.

Essa pandemia do medo seria, em nossa análise, fruto de um mecanismo de dominação que assume uma conotação política, mais precisamente biopolítica, que, como já nos indicou Foucault (2008), busca docilizar e manipular os corpos e gerir a vida. Convivemos com um medo midiatizado e sensacionalista que se naturaliza e passa a fazer parte de nosso dia a dia.

\footnotetext{
${ }^{1}$ Pandemia, no campo médico, é uma doença que se espalha através das populaçōes e levanta ameaças fatais à humanidade.
} 
Algumas pesquisas (Chauí, 1987; Santos, 2003; Breilh, 2004; Teixeira 2004; Bauman, 2008; Bianchi, 2015; Santos, 2019) indicam que o medo vem aumentando no presente. $E$ isso não é trivial, pois uma sociedade amedrontada tem medo de falar, de se expressar, tem medo dos pobres, dos marginais, de todos aqueles que, segundo discursos midiáticos, podem nos "fazer algum mal". Medo como instrumento de dominação que assume uma conotação antipolítica, nas formulações de Arendt (2010), uma vez que, numa sociedade amedrontada, prevalecem interesses individualistas que minam o espaço público, celeiro de liberdade.

Essa produção de medo gera um mal-estar, vivido, muitas vezes, como catástrofe, mas pode, também, ser experimentado como germe para a construção de realidades outras, conduzindo-nos a um movimento de resistência/criação, de forma a fortalecer e aquecer redes que possam enfrentar esse estado de coisas. Redes que não produzam efeitos de homogeneização e de equalização, mas redes quentes, pautadas num funcionamento no qual a dinâmica conectiva seja geradora de efeitos de diferenciação, ou seja, uma rede heterogenética. Nesse sentido, a experiência do coletivo, do público, pode "ser retomada como plano de produção de novas formas de existência que resistem às formas de equalização ou de serialização próprias do capitalismo” (Benevides \& Passos, 2005).

Em nosso caso, no Brasil, alguns acontecimentos acionaram e, ou, reforçaram essa pandemia, tais como o processo de impeachment da presidenta Dilma Rousseff, conflitos acirrados nas redes sociais, a esquerda rachada, microfascismos de diferentes ordens, uma ultradireita no governo do País, a força dos movimentos que denominamos de identitários, tais como os movimentos negro, feminista e LGBT+, que considerávamos como movimentos perigosos de afirmação de processos de produção de identidades.

Em várias situações em sala de aula hoje, na Universidade Federal do Espírito Santo, onde lecionamos há 41 anos, os alunos apontam um racismo institucional que se materializa em nossas práticas de sala de aula, indo desde a ênfase em determinadas temáticas, que se pautam exclusivamente em referências eurocentradas, a falas racistas enunciadas por nós, professores. Ao longo do percurso na universidade, sempre nos consideramos aliados das pautas que fazem o enfrentamento de práticas racistas, homofóbicas e machistas, no entanto os alunos, alunas indicavam modos de funcionamento em sala de aula como práticas racistas: "Professora, a senhora está sendo racista!". Perplexidade. Tristeza. Angústia. Sentimentos produzidos ao ouvir dos alunos que jogamos em times diferentes. Num primeiro momento, reagimos de forma ressentida a essas intervenções. $\mathrm{O}$ mal-estar acabava, muitas vezes, produzindo ressentimento. Não sabíamos o que fazer com esse mal-estar, mas, certamente, o ressentimento 
não era um afeto micropolítico que pudesse nos arrancar de lugares instituídos em que nos encontramos. Muitos processos judiciais foram acionados pelos militantes desses movimentos. Mas a judicialização também não nos parecia um bom caminho. Era preciso fazer o enfrentamento dessas situações com base em estratégias que viabilizassem um reposicionamento subjetivo de professores, professoras, alunos e alunas. Era preciso ser inatual para ser contemporâneo.

Como compor com esses movimentos que chamamos, muitas vezes, de identitários? Como articular com lutas identitárias e suas posiçôes, muitas vezes consideradas violentas, sem pretender colonizá-las a partir de nossos referenciais políticos-conceituais-metodológicos? Como produzir conexões com o que se passa no contemporâneo sem impor nossas medidas para avaliálos? Enfim, vivemos um certo desespero pelo fato de um chão que nos parecia firme e consolidado estar ruindo. Acreditávamos que nossas conquistas eram indestrutíveis, no entanto experimentamos incertezas, falências, desmonte de nossos referenciais conceituais, consequentemente, medo.

Mas, afinal, o que colapsa? Que colapso é esse? O colapso não seria um processo de exaustão de um modelo que esgotou suas possibilidades repertoriais, exigindo de nós seu abandono? (Costa \& Mizoguchi, 2018)

Como já indicamos em outra ocasião (Amador, Barros, \& Silva, 2018), vivemos uma espécie de zona-limite, colapso-catástrofe, experiência paradoxal, pois afirmamos, ao mesmo tempo, enfraquecimento-paralisia e fortalecimentomovimento. Uma espécie de violência tenta impedir um certo fluxo de prosseguir, por perturbação das conexões até então estabelecidas e, ao mesmo tempo, um impulso para o agir. Sim, uma experiência paradoxal: falência de um modelo, uma espécie de esgotamento das possibilidades de variação existencial e convocação à criação de outros modos de viver. Esgotamento de certa "molaridade instituída" que nos convoca a uma invenção radical de modos de fazer a vida andar e nos conduz a pensar o colapso como uma dimensão necessariamente criadora. Há aí um movimento interessante, ou seja, um processo que nos arranca violentamente de uma tranquilidade presumida, como se nossas conquistas fossem definitivas e inquestionáveis. Isso tudo gera insegurança, uma vez que vivemos o desfazimento de laços sociais que pensávamos consolidados.

Esse mal-estar precisa nos convocar a pensar sobre o que estamos vivendo e, então, criar estratégias e fortalecer as que já estão em curso. Afinal, como nos lembra Foucault (2004), não é inútil revoltar-nos. É preciso viver esse mal-estar como embriōes de futuro.

Buscamos, então, pensar o colapso como um esgotamento e não como um cansaço. Lembrando Deleuze (2010), o esgotado é muito mais que o cansado. O 
cansado esgotou toda a realização, e o esgotado esgota todo o possível. O cansado não disporia mais de qualquer possibilidade. $\mathrm{O}$ esgotamento é o chamamento da existência clamando por novas formas de vida, refere-se à criação de um "para além de si”. Aquilo que se esgota abre espaço para a criação. Somos um excesso que quer reinventar conexões. Há vacúolos de devir: a terra está fértil novamente (Trindade, 2017).

Como, então, tomar o que vivemos como um esgotamento, um acontecimento, como abertura a partir da qual emerge um possível criado pelo acontecimento?

Como nos diz Rolnik (2019), embriôes de mundos tencionam e desestabilizam os modos de existência em que a vida se encontra corporificada no presente. O mal-estar gera um nó na garganta: este é um sinal de alarme fundamental que a vida aciona para convocar o desejo a agir de modo a recobrar um modo de vida ativo, evitando os modos reativos de enfrentar esse mal-estar. Já uma micropolítica reativa desvia a força do desejo de seu destino criador e é canalizada para os interesses pautados na lógica do capital e tem, fundamentalmente, como recurso disponível para avaliar o que se passa a reprodução de modos de vida preestabelecidos.

Em meu entendimento, uma forma de canalizar criadoramente essa força do desejo é construir coletivos fortes e redes afetivas de trabalho, redes quentes de amizade. Amizade que, como nos diz Agamben (2009, p. 92), tem estatuto ontológico e político: "A amizade é a condivisão que precede toda divisão, porque aquilo que há para repartir é o próprio fato de existir, a própria vida”. Uma micropolítica ativa implica o fortalecimento dessa condivisão, uma partilha sem objeto, um "com-sentir" que constitui a política.

Arriscaríamos, aqui, uma hipótese: os coletivos amedrontados, que não "comsentem", são efeitos dos laços que estão se desfazendo e se enfraquecendo, pois o medo seria proveniente do esfriamento das redes. Eis o paradoxo: coletivos sem laços sociais, foi sequestrado o coletivo? O que fazer para que a vida coletiva possa fluir na contramão do isolamento que as políticas totalitárias imprimem? Como funcionar na contramão de interesses individualistas? Propomos uma direção de resposta: ativando uma micropolítica ativa, retirando-nos de uma pretensa estabilidade, lançando-nos no laborioso trabalho de transformação do que está posto, que é a própria condição do viver. É preciso ativar uma micropolítica que nos ajude a detectar o intolerável e buscar formas de combatê-lo.

É no enfrentamento de tal quadro que enfatizamos o sentido público de nossas práticas nas universidades públicas, ênfase na produção de um comum, de forma que possamos enfrentar esse medo que o isolamento acaba produzindo. É a partir de uma micropolítica ativa, tomando esse medo como um alarme 
vital (alarme que surge sempre que a vida está sendo violentada), é que podemos reverter essa pandemia e resistir criando coletivos, fortalecendo redes afetivas de trabalho, e isso não se faz apenas no plano macropolítico de enfrentamento do Estado, o que é importantíssimo, mas não suficiente.

\section{O MEDO COMO MODO DE PRODUÇÃO SUBJETIVA: EFEITO DE POLÍTICAS TOTALITÁRIAS}

Para pensar essa questão do medo a partir de uma micropolítica ativa, fomos buscar em Arendt (2009) algumas pistas, pois ela, em sua experiência com a violência do totalitarismo nazista, em sua passagem pelo campo de concentração, aciona uma micropolítica da maior importância. Ela não se colocou na posição de vítima, tomada por sentimentos de ódio e de ressentimento. Ao contrário, enfrentou tal violência mantendo ativo o pensamento, decifrando os afetos do nazismo. É nesse exercício de pensamento que suas formulações nos ajudam a pensar o medo que experimentamos a partir de certa gestão da política no contemporâneo, em especial no atual governo do Estado brasileiro.

Cabe lembrar que o totalitarismo, na obra de Arendt, é uma categoria de explicação filosófica e não simplesmente um fenômeno histórico. $\mathrm{O}$ totalitarismo seria uma organização governamental e sistemática da vida dos humanos, considerando-os controláveis e descartáveis. É uma forma de governar sustentada no pressuposto do extermínio de setores da população considerados desnecessários e não apenas na sua opressão, trata-se, principalmente, de uma descartabilidade humana.

A vida nos governos totais é tomada na sua dimensão de vida nua, ou seja, uma vida reduzida à sobrevivência, à sua dimensão biológica (Agamben, 2007b). Busca-se eliminar as instituiçôes que possam dar abrigo à solidariedade, à ação. Seu principal objetivo é a destruição do mundo comum, como as experiências nos partidos, com a arte, nos sindicatos e em outras formas de organização. Tais governos constituem-se baseados na propaganda, na espetacularização, na atomização, na solidão, na padronização e na redução do humano à vida besta, a uma sobrevida. A preocupação de Arendt (2009) era de que os regimes totais predominassem nas sociedades contemporâneas. Regimes que concebem os humanos apenas como seres que sobrevivem, regimes que colocam critérios para a escolha dos merecedores da vida, exterminando os considerados impuros e indignos.

Isso levou Arendt (2009) a afirmar que, nos regimes totalitários, o medo assume papel importante, assume uma dimensão nova, viabilizando-se num 
ordenamento social, segundo o qual, cria-se uma sociedade atomizada, que dificulta, restringe, limita o poder de agir em conjunto, que é condição humana. Todavia uma ação política é indissociável da liberdade, que não tem como fundamento o controle, mas o aquecimento de redes. $\mathrm{O}$ medo surge, exatamente, quando os humanos se separam, uma vez que, quando agem juntos, são fortes.

Esse debate nos remete à experiência vivida durante o segundo turno para eleiçôes presidenciais no Brasil, em 2018. Estávamos, nessa ocasião, em Cuba, juntamente com um grupo de brasileiros, participando de um Simpósio Franco-Latino-Americano sobre Clínicas do Trabalho. Os cubanos, com grande apreensão, acompanharam-nos ao longo da apuração. "O resultado dessas eleições no Brasil impactará não só as políticas no Brasil, mas também em toda a América Latina”, diziam os cubanos. Ao lado dos brasileiros, acompanhavam, atentamente, os resultados da eleição em cada recanto brasileiro.

Ao fim da apuração, uma onda de medo se espalhou entre os brasileiros que, imediatamente, começaram a sair de todas as redes sociais em que estavam conectados. Um pânico se instalou, e uma preocupação com as possíveis retaliações políticas, que poderiam ocorrer a partir do resultado das eleições, levou muitos a se desconectarem de suas redes. Esfriamento das redes. Isolamento. Efeitos de uma política totalitária. Muitos se desfaziam do que haviam comprado ao longo da estada em Cuba como souvenir daquele país, pois se acreditava que tais recordações traziam as marcas de um pensamento que não seria mais admissível no Brasil, conforme já havia indicado o então candidato à Presidência. Souvenirs que passariam a ser considerados indícios de uma posição política não admitida pelo novo governo brasileiro. As formas de diminuição de potência de indivíduos e coletivos não são, portanto, efeitos colaterais das políticas totais, mas uma de suas obras mais importantes, pois enfraquecer indivíduos e coletivos é necessário para melhor dominá-los.

Ao contrário, nosso poder de agir surge no momento em que as pessoas se reúnem e agem de comum acordo, o que não implica homogeneidade, mas pluralidade. O poder seria essa dimensão criadora de homens e mulheres livres e a liberdade à capacidade de agir com os outros, uma política fundadora do mundo comum, o que implica tensionamentos, conflitos, diferença, diferenciação, heterogênese. Fazer política é resistir às tentativas de destruição do mundo comum que é, exatamente, por onde o novo surge. Fazer política é, dessarte, criação de algo novo. Para Arendt (2006, p. 123), "A política trata da convivência entre diferentes. Os homens (e as mulheres) se organizam politicamente para certas coisas em comum, essenciais num caos absoluto, ou a partir do caos absoluto das diferenças". 
Arendt (2006) nos diz, ainda, que política é vida ativa, é vida qualificada e não vida nua. Vida qualificada que é forjada no encontro e no confronto de pluralidades, do debate livre em um espaço público. O que nos torna seres políticos é nossa capacidade para ação, nossa capacidade de nos reunir e produzir grupalidade, agir em comunhão. No entanto, para que haja ação, é necessário que os humanos se comuniquem, interajam e se expressem por meio do discurso no espaço público. Logo, se o coletivo é sequestrado, surge medo, associado ao terror produzido pelas ideologias totalitárias, cujo objetivo é "abafar com uma onda de terror indizível todas as tentativas de oposição organizada" (Arendt, 2009, p. 104). Nessa direção, a liberdade tem caráter de imprevisibilidade, "o fato de homens e mulheres serem capazes de agir significa que se pode esperar deles o inesperado" (Arendt, 2009, p. 191). Os indivíduos estão num movimento de eterno recomeço, sempre impelidos a agir.

Leiamos juntos o que a filósofa nos diz:

O medo [. . . está fundamentalmente ligado àquela ansiedade que sentimos em situações de completo isolamento. Essa ansiedade revela o outro lado da igualdade, e corresponde à alegria de dividir o mundo com nossos iguais. A dependência e a interdependência que nos são necessárias para realizar o nosso poder (o montante de força estritamente nossa) se tornam fonte de desespero sempre que, em total isolamento, percebemos que [sozinhos não temos força] (cf. Arendt, 2011, p. 355).

Isolado, o indivíduo se encontra inoperante, sujeitado às estruturas políticas, e regimes totalitários se sustentam conforme perseguem o comprometimento radical da possibilidade de participação na esfera pública, pela destruição do espaço entre os humanos. Podemos dizer, então, que é preciso investir na alternativa de resistência pela insistência da ação, evitando a resignação. $\mathrm{O}$ medo expressa o desespero pela impossibilidade de ação e descrença na possibilidade da emergência de novas empreitadas. Se, para Arendt, a ação é a condição plena dos humanos realizarem o improvável e a ação política a aptidão para agir em concerto num mundo compartilhado, o medo seria uma forma de destruição do que há de humano em homens e mulheres.

Logo, no enfrentamento desse quadro, que estamos chamando de pandemia do medo, é preciso fortalecer alguns projetos que tenham como direção prioritária a tarefa de produzir nas universidades redes aquecidas de trabalho que se constituam como luta, combate a essa pandemia e seja produção de heterogênese e de democracia. Projetos pautados numa micropolítica de enfrentamento das violências e subjetivação do medo no contexto da ciência e da democracia nas Instituiçõos Federais de Ensino Superior (IFES) no Brasil. 


\section{O PROGRAMA DE FORMAÇÃO E INVESTIGAÇÃO EM SAÚDE E TRABALHO: EXERCITANDO UMA MICROPOLÍTICA ATIVA NUMA INSTITUIÇÃO FEDERAL DE ENSINO}

Nos últimos dez anos, na Universidade Federal do Espírito Santo, temos desenvolvido uma pesquisa-intervenção no Município da Serra-ES que busca caminhar na direção que indicamos até aqui neste artigo. Trata-se de uma pesquisa, intitulada Programa de Formação e Investigação em Saúde e Trabalho (PFIST), que vislumbra uma política, no sentido arendtiano, visando a um agir como um meio de compartilhar, em concerto, as questôes da vida comum, a partir da afirmação de um tempo oportuno, uma kairologia. Um projeto que perspectiva produção de grupalidade por meio de uma política da amizade.

O PFIST se constitui como uma ação que se fez possível ao acionarmos a instituição de Comissões de Saúde do Trabalhador da Educação (Cosate) no Município de Serra. Com esse objetivo, instituímos um fórum que congrega diversos segmentos envolvidos com essa rede municipal de educação básica, que entendem ser a saúde do trabalhador, da trabalhadora um aspecto imprescindível na discussão acerca da qualidade da educação pública.

A proposta, elaborada a muitas mãos ${ }^{2}$, tem sido empreendida sob a coordenação de pesquisadores vinculados ao NEPESP-UFES e constitui-se como uma pesquisa-intervenção. A criação do referido programa se deu com o intento de que o trabalho das Cosate implicasse no delineamento de estratégias para que os canais de comunicação fossem ampliados entre pesquisadores da UFES e trabalhadores da rede municipal de ensino de Serra, mas também entre os próprios trabalhadores e trabalhadoras da rede. Essa ampliação contempla o estabelecimento e fortalecimento de parceria com outros equipamentos sociais bem como o envolvimento dos sujeitos que compõem a comunidade escolar, incluindo alunos e familiares. Trata-se de um empreendimento que está inserido no processo de construção, implementação e consolidação de uma política pública.

Insistimos na possibilidade de que esses trabalhadores e trabalhadoras gestem seu trabalho, construam um espaço, um entre onde se daria a política (Arendt, 2009). A aposta é de que essas comissóes de saúde produzam permanentemente a possibilidade de recriar novas formas de trabalhar e de viver, buscando evitar o risco de tornar-se mecanismo de contenção, de aprisionamento e de diminuição da potência de vida. As ações para instituição das Cosate pretendem ir além do

\footnotetext{
${ }^{2}$ Participaram da elaboração do projeto de formação: representantes do Centro Referência em Saúde do Trabalhador do Espírito Santo (CEREST-ES), Fundação Jorge Duprat e Figueiredo (FUNDACENTRO), Divisão de Medicina e Segurança do Trabalho da Prefeitura Municipal de Serra (DMST-Serra), Núcleo de Estudos e Pesquisas em Subjetividades e Políticas da Universidade Federal do Espírito Santo (NEPESP-UFES) e outros profissionais ligados à SEDU-Serra.
} 
meramente provável, mas acreditar na possibilidade de um novo começo, de um agir do qual pode se esperar o inesperado.

A Cosate, pensada para ter um funcionamento coletivo, dialógico e aberto, investe nas possibilidades de suspensão de certos dispositivos de poder e, nesse sentido, afirma as comissóes como disparadoras de diversos movimentos coletivos. Perspectivamos a criação de canais de conversa e sustentação do pensar e agir juntos, de forma a comportar novas formas de participação não instituídas e derivar ações de profanação (Agamben, 2007a).

Ao questionar e sugerir nova forma de organização do trabalho, ao profanar os modos habituais de trabalhar nas escolas, a Cosate possibilita fazer um novo uso, aventurar-se, lançar-se na empreitada de criar modos de ampliação do dialogismo, buscando ação sem esperar que os efeitos emerjam somente ao fim do projeto. Na direção de Agamben (2007a), arriscamos dizer que a Cosate é um jogo, uma atividade como

Puro meio, ou seja, uma prática que, embora conserve tenazmente a sua natureza de meio, se emancipou de sua relação com uma finalidade, esqueceu alegremente seu objetivo, podendo agora exibir-se como tal, como meio sem fim. Assim a criação de um novo uso só é possível ao homem se ele desativar o velho uso, tornando-o inoperante (Agamben, 2007a, pp. 74-75).

Conforme Barros, Brito, Freitas, Gotardo e Araújo (2016), lançar-se ao desafio de constituição de Comissões de Saúde do Trabalhador da Educação oportuniza disposição para criar, para inventar, profanar dispositivos de poder que sacralizam a gestão do trabalho, o que requer estar em relação, "comsentir”. Profanar é uma ação micropolítica, é algo que não podemos planejar ou garantir, pois é a atualização do imprevisível. De abertura ao improvável. Profanar implica fazer novo uso do que foi sacralizado, uma ação criadora que se dá em relação, é fazer uso livre do mundo e fazer frente aos dispositivos de poder que perspectivam o isolamento, o esfriamento das redes sociais. Profanar é uma aposta na constituição de possibilidades de suspensão de certos dispositivos de poder e, nesse sentido, a pista é disparar diversos movimentos coletivos, por meio de canais de conversa, da constituição de projetos de pesquisa ou extensão voltados para a produção de políticas públicas que sustentem um pensar e agir juntos, derivando ações de profanação, que, como nos diz Agamben (2007a, p. 9), é "pensar e promover o avesso da vida nua, a potência da vida e a vida humana como potência de ser e de não ser". Engendrar uma ação política efetivamente democrática na produção de conhecimento nas universidades, conforme nos sugere o título deste artigo, implica o gesto de conviver, pois conviver é mais do que estar no mesmo espaço, conviver é "com-sentir", sentir junto (Agamben, 
2009). Ação política como liberdade tem dimensão de conversa, de proximidade e demanda tempo, demanda compartilhamento de um novo modo de viver e trabalhar que se faz criando comum. Trata-se de um modo de pensar a vocação humana de se associar aos outros por meio do diálogo, para pensar, julgar e agir.

Assim, nas ações de implantação das Cosate, a prioridade é acionar nossa capacidade de dialogar com todos os profissionais que trabalham na escola, com os trabalhadores e trabalhadoras do órgão central da Secretaria de Educação do Município, com o Sindicato dos Professores do ES e demais parceiros interessados em intervir na rede de ensino da cidade, ouvindo, compondo com eles, agindo para pôr a organização do trabalho em suspensão, compartilhando experiências, problemas, criando, em conjunto, estratégias e caminhos de ação, tendo como desafio primordial a produção de uma grupalidade (Barros, 2007).

O projeto do PFIST é de que as Comissóes de Saúde do Trabalhador da Educação sejam uma possibilidade de experiência pública que possibilite a potência de exercer política, produzindo a si mesmo e formas potentes de relacionar-se com o trabalho, abrindo chances de desmontagem dos mecanismos que capturam a ação humana.

Conforme Barros et al. (2016), o que nos movimenta nessa empreitada é a convicção no movimento que se abre para um possível que vem, pois não se trata de alçar formas instituídas de ação tão somente. Perseguir uma política, no sentido arendtiano, implica construir meios de compartilhar em concerto as questôes da vida comum, afirmando um tempo oportuno. Aqui estaria, em nossa análise, pistas para uma micropolítica ativa, pois não bastam ações no nível macropolítico no enfrentamento desses totalitarismos que temos vivido. É preciso investir na construção, implementação e consolidação de políticas públicas, que não equivalem às políticas de Estado que se efetivam por meio da máquina estatal e nem às de governo, empreendidas em mandatos, com projetos de cunho partidário, mas uma política sustentada pelo plano coletivo que atravessa Estado, governos, movimentos sociais, a vida cotidiana enfim. Coletivo não no sentido de massa de pessoas, mas como afirmação de direitos para "qualquer um". Esse fora do Estado seria o plano do coletivo que se apresenta como uma questão pública. Estado e governo não são tomados, aqui, como coincidentes, uma vez que o domínio do Estado e do público não se justapõem. Do modo como entendemos, o plano do público diz respeito à experiência concreta dos coletivos, é aquele construído a partir das experiências de cada homem e cada mulher. 
Então, é possível a construção de uma experiência pública compartilhada em tempos nos quais a experiência ${ }^{3}$ se encontra em crise? $\mathrm{O}$ que nos inquieta? Diria com Arendt (2010) que o que nos inquieta é uma desresponsabilização pelo mundo como verdadeira crise da liberdade e do sentido de público ou do "mundo comum". Vivemos hoje numa sociedade em que o governo persegue a redução da esfera política, mostrando-se, muitas vezes, indiferente às questóes públicas, uma sociedade que se torna cada vez mais atomizada, individualista, intimista. Em alguma medida, a construção do mundo comum fica, diante desse panorama, fragilizada e os sentidos tecidos pelo compartilhamento das experiências se diluem.

Na pesquisa que realizamos, buscamos nos jogar num exercício de produção de uma política que demande compartilhamento da existência, de modo a não nos deixar capturar pelos dispositivos que buscam nos fazer acreditar que toda política caminha para a catástrofe. Perspectivamos enfrentar o colapso no contemporâneo como germes para a instituição de ações políticas.

Doravante, uma micropolítica ativa implica ir além do meramente provável, e acreditar na possibilidade de um novo começo, de um agir do qual pode se esperar o inesperado.

Nas conformações dos modos de vida atuais, o desafio que se coloca aos movimentos que intencionam a construção de uma política pública é o de criar condições de possibilidade para a produção dessa experiência, bem como a construção de uma narratividade que a permita germinar, e essa seria uma pista para orientar nossas açôes, visando à profanação dos dispositivos regulatórios hegemônicos (Barros, Brito, Freitas, Gotardo, \& Araújo, 2016).

É na experimentação desse paradoxo que sugiro pensar o enfrentamento dessa pandemia do medo. E, retomando a questão foucaultiana, nós nos perguntamos: é inútil revoltar-se? Foucault (2004) lembra-nos que enxergar no fracasso político a inutilidade da revolta é desprezar o esforço de todos e todas que lutam e até morrem para a criação de outras possibilidades de vida. Ele nos convoca a uma atenção ao presente, uma interrogação sobre a atualidade. Ser inatual no contemporâneo.

A revolta é devir, entusiasmo, sonho. Um devir revolucionário é uma oportunidade de conjurar a vergonha e responder ao intolerável. Para Foucault (2004), a história está sempre aberta à revolta, a se rasgar e criar novos tempos e, assim, ficarmos atentos ao que "acontecimentaliza" para poder escutar o som da revolta no presente. Ao discordar daqueles que dizem que é inútil revoltar-se,

\footnotetext{
${ }^{3}$ Experiência, como compartilhamento público, tem caráter político da comunhão entre humanos. A transmissão, então, não se afirma como troca de informações ou do repasse delas a outro. Transmissão vincula-se à ideia de que algo germina.
} 
insurgir-se, entendemos, com Foucault, que a resistência é a capacidade que a força tem de entrar em relaçôes não calculadas pelas estratégias que vigoram no campo político. Resistir, então, não é reagir, pois, quando reagimos, damos resposta àquilo que o poder quer de nós. Quando resistimos, criamos possibilidade de existência a partir de composição de forças inéditas. Resistir é sinônimo de criar, portanto não aceitação dos modos de subjetividades modelares; é possibilidade de mudar práticas tidas como intoleráveis; é uma experiência de subjetivação e uma experimentação de liberdade que exige coragem para tirar de nossa raiva em relação ao inaceitável a energia necessária para combatê-lo e espantar o medo. Retomando o tema de nossa conversa, resistir/criar, entendemos que liberdade não pode ficar reduzida à capacidade de se opor ou de não permanecer em dada relação por nos abstermos de autonomia, ou abdicarmos de uma ação. Liberdade é ativar nossa potência de agir em concerto.

Nessa direção, resistência não é confronto com o inimigo, o que, às vezes, precisa ser, mas sobretudo combate, luta com a adversidade, é usar estratégias que desarmem o inimigo. As resistências meramente reativas negam, conservam e restauram um estado de coisas, já as resistências ativas ativam a alegria da invenção e a afirmação da diferença. Como indica Safatle (2017): os sistemas vitais são marcados por uma permanente reordenação, instituindo novas normatividades que perseguem a mudança radical dos modelos de regulação, afirmando sua capacidade transitiva. Essa cena se passa fora do tempo do capital. Trata-se da vida em sua soberania insubmissa que nos puxa para fora desse tempo.

Nossa aposta numa micropolítica ativa implica, portanto, desestabilização da subjetividade, insubmissão aos modelos prêt-à-porter de subjetividade, de forma que um mundo larvário possa germinar, o que somente se efetiva por meio de um processo criador que transforma subjetividades e também nosso campo relacional. Ela é sempre pontual, local, precisa, limitada e requer coragem de direcionar o poder de existir liberado pela indignação combativa para cultivar poderes dignos de existência, e isso tudo requer perseverança, coragem de liberdade.

Os processos de subjetivação, doravante, são uma forma de resistir, uma busca prática de outro estilo, de outro modo de viver, outros modos de existencialização. Afinal, onde estariam os germens para essa construção? Essa é a pergunta que precisamos fazer de forma a pensar essa dimensão do colapso como desmonte de um mundo, dando passagem a outras sensibilidades e ter coragem de forjar outros modos de fazer a vida andar, outros modos de subjetivação, o que acreditamos ser possível quando construímos laços sociais, quando fortalecemos coletivos e aquecemos redes. O milagre está à espreita, lembra-nos Arendt (2009). 


\section{REFERÊNCIAS}

Agamben, G. (2007a). Profanações. São Paulo: Boitempo.

Agamben, G. (2007b). Estado de exceção. São Paulo: Boitempo.

Agamben, G. (2009). O que é o contemporâneo? E outros ensaios. V. N. Honesko (Trad.). Chapecó: Argos.

Amador, F. S., Barros, M. E. B., \& Silva, F. H. (2018). A respeito de colapso, de política e de trabalho. In M. E. B. Barros, L. A. Costa, \& D. H. Mizoguchi (Org.), Colapso clínico-político do comum na Contemporaneidade. (pp. 29-48). Curitiba: CRV.

Arendt, H. (2006). O que é política? Rio de Janeiro: Bertrand Brasil.

Arendt, H. (2009). A promessa da política. Rio de Janeiro: Difel.

Arendt, H. (2010). A condição humana. Rio de Janeiro: Forense Universitária.

Arendt, H. (2011). Compreender: formação, exílio e totalitarismo. São Paulo: Companhia das Letras.

Barros, M. E., Brito, H., Freitas, M. C., Gotardo, S. M., \& Araújo, V. (2016). O processo de formação de comissões de saúde do trabalhador da educação: experiência e política. Revista Ciências Humanas, 50(2), 334-353.

Barros, R. B. (2007). Grupo: a afirmação de um simulacro. Porto Alegre: Sulina.

Bauman, Z. (2008). Medo líquido. Rio de Janeiro: Jorge Zahar.

Benevides, R., \& Passos, E. (2005, março-agosto). A humanização como dimensão pública das políticas de saúde. Interface - Comunicação, Saúde, Educação, 9(17), 389-394.

Bianchi, Á. (2015). Buckley Júnior., Kirk e o renascimento do conservadorismo nos Estados Unidos. In S. V. Cruz, A. Kaysel, \& G. Codas (Org.), Direita, volver! O retorno da direita e o ciclo político brasileiro. (pp. 247-260). São Paulo: Fundação Perseu Abramo.

Breilh, J. (2004). El abandono de equidad: domando la salud pública. In International Conference Rethinking "the Public" in public health: neoliberalism, structural violence, and epidemics of inequality in Latin America. San Diego: Center for Iberian and Latin American Studies, University of California. 
Chauí, M. (1987). Sobre o medo. In S. Cardoso. (Org.). Os sentidos da paixão. (pp. 35-76). São Paulo: Companhia das Letras.

Costa, L. A., \& Mizoguchi, D. H. (2018). Colapso: esgotamento e passagens. In M. E. B. Barros, L. A. Costa, \& D. H. Mizoguchi (Orgs.), Colapso clinicopolítico do comum na Contemporaneidade. (pp. 107-126). Curitiba: CRV.

Deleuze, G. (2010). Sobre o teatro: um manifesto de menos, o esgotado. F. Saadi, O. Abreu, R. Machado. (Trads.). Rio de Janeiro: Zahar.

Foucault, M. (2004). É inútil revoltar-se? In M. Foucault. Ditos \& escritos V: ética, sexualidade, política. (pp. 77-81). Rio de Janeiro: Forense Universitária.

Foucault, M. (2008). Microfisica do poder. Rio de Janeiro: Graal.

Rolnik, S. (2019). Para que serve pensar? In Palestra proferida no Encontro do Grupo de Trabalho Subjetividade Contemporânea da Associação Nacional de Pesquisa e Pós-graduação em Psicologia (ANPEPP) - Resistir criando nas universidades: dispositivos de formação e produção de subjetividade, realizado nos dias 25 e 26 abril de 2019 na PUC-SP, Campus Perdizes, São Paulo.

Safatle, V. (2017, 17 março). O estado de mal-estar social. Folha de São Paulo.

Santos, L. O. (2003). O medo contemporâneo: abordando diferentes dimensões. Revista Psicologia, Ciência e Profissão, 23(2), 48-55.

Santos, R. O. (2019, janeiro-junho). Medo, paranoia, macarthismo e o século XXI: usando o episódio 22 de além da imaginação em sala de aula. História: Questôes \& Debates, 67(1), 283-307.

Teixeira, R. R. (2004). As redes de trabalho afetivo e a contribuição da saúde para a emergência de uma outra concepção de público. In Research conference on rethinking "the public" in public health: neoliberalism, structural violence, and epidemics of inequality in Latin America. San Diego: Center for Iberian and Latin American Studies, University of California.

Trindade, R. (2017). Afetos (bio)políticos: esgotamento. Razão Inadequada, 21 maio 2017. Recuperado a partir de https://razaoinadequada.com/2017/05/21/ afetos-biopoliticos-esgotamento/ 